\title{
Experiment using variable reactor of rectifier type superconducting fault current limiter with a short- circuited trigger coil
}

\section{AUTHOR(S):}

Hoshino, T; Salim, KM; Muta, I; Nakamura, T; Yamada, $M$

\section{CITATION:}

Hoshino, T ... [et al]. Experiment using variable reactor of rectifier type superconducting fault current limiter with a short-circuited trigger coil. IEEE TRANSACTIONS ON APPLIED SUPERCONDUCTIVITY 2004, 14(2): 626-629

\section{ISSUE DATE:}

2004-06

URL:

http://hdl.handle.net/2433/39953

\section{RIGHT:}

(c)2004 IEEE. Personal use of this material is permitted. However, permission to reprint/republish this material for advertising or promotional purposes or for creating new collective works for resale or redistribution to servers or lists, or to reuse any copyrighted component of this work in other works must be obtained from the IEEE. 


\title{
Experiment Using Variable Reactor of Rectifier Type Superconducting Fault Current Limiter With a Short-Circuited Trigger Coil
}

\author{
Tsutomu Hoshino, Khosru Mohammad Salim, Itsuya Muta, Member, IEEE, Taketsune Nakamura, and
} Masato Yamada

\begin{abstract}
A rectifier type superconducting fault current limiter using an additional shot-circuited trigger coil has been studied. Such reactor consists of two well-coupled superconducting coils; the main coil and trigger coil. The main coil is connected to the DC link of the bridge circuit while the trigger winding is always short-circuited. As the trigger coil is short-circuited the reactor shows low inductance in normal operation. A change of load current due to load change or some other reasons increase the shot-circuit current but inductance value remains unchanged as long as the trigger coil remains in superconducting state. During fault time, the fault current yields super to normal transition current in the secondary (trigger) winding and the trigger coil quenches. Thus higher impedance appears in the main coil that limits the fault current. The advantage of using an additional trigger coil with the main coil is that it reduces the impedance of the current limiter at normal operation and therefore reduces voltage drop across the limiter. To enhance the coupling factor of the windings iron core can be used. If the magnetic path is closed with the iron core even with some air gap it can be saturated during fault time because of the high DC current but would effectively reduce leakage reactance during normal operation. In this paper a small-scale experimental result of this type of current limiter has been presented.
\end{abstract}

Index Terms-Bridge reactor, fault current limiter, superconducting-to-normal $(\mathrm{S} / \mathrm{N})$ transition, superconductor, trigger coil.

\section{INTRODUCTION}

$\mathbf{M}$ ANY circuits and topologies on the superconducting fault current limiter (SFCL) are available today and some of them are known as rectifier types [1], [2]. We have been studying on rectifier type superconducting fault current limiter using variable reactor [3]-[5]. The reason why variable reactor is considered is that, it can produce low inductance value during normal operation. The most of the time the SFCL remains in waiting condition therefore minimum line voltage drop and low power loss is most important during waiting time. The DC current of the rectifier type SFCL will minimize the ac loss of the superconducting coils and the core materials of the

Manuscript received October 20, 2003. This work was supported in part by the 21th Century Center of Excellent (COE) program in Japan (no. 14213201) and by The Kansai Electric Power Company, Inc.

T. Hoshino, K. M. Salim, I. Muta and T. Nakamura are with the Department of Electrical Engineering, Graduate School of Engineering, Kyoto University, Nishigyo-Ku, Kyoto 615-8510, Japan (e-mail: hoshino@kuee.kyoto-u.ac.jp; khosru@asl.kuee.kyoto-u.ac.jp; muta@kuee.kyoto-u.ac.jp; tk_naka@kuee.kyoto-u.ac.jp).

M. Yamada is with the General R\&D Center, Kansai Electric Power Company, Amagasaki, Hyogo 661-0974, Japan (e-mail: K431639@kepco.co.jp).

Digital Object Identifier 10.1109/TASC.2004.830003

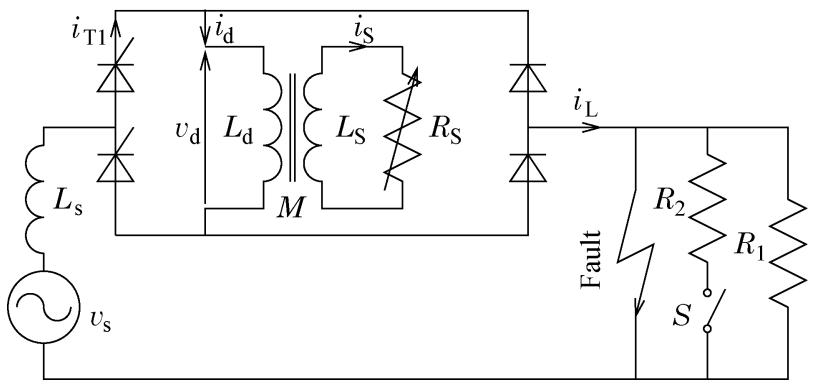

Fig. 1. The circuit diagram of rectifier type superconductive fault current limiter with short-circuited trigger coil.

reactor. The low inductance value during normal operation will ensure the low voltage drop across the SFCL. Another advantage of the rectifier type SFCL is that it could be used as a circuit breaker along with its current limiting property. A diodethyristor based hybrid bridge circuit is capable of shutting down the power line from the load by removing the trigger signals from the gate of the thyristor pair. Therefore, the SFCL could work as a fast circuit breaker as well as a current limiter. This advantage would allow in designing the SFCL for minimum current limiting period ( 1 cycle or less) that could minimize the size and cost of the system. In this paper the preliminary experimental results of rectifier type SFCL with additional short-circuited trigger coil has been presented.

\section{OPERATIONAL DESCRIPTION}

The schematic diagram of the SFCL is shown in Fig. 1. The main coil of the reactor is fed by the rectified line current in series with the load. The trigger coil always remains short-circuited. The short-circuited winding cancel the flux generated by the ac component of the main coil current. For this reason the rate of change of flux inside the reactor caused by the main coil current will be canceled by the trigger coil. This behavior of the two winding reactor causes low inductance during normal operation. The low inductance means low voltage drop across the SFCL at normal and load changing time. At fault time, the trigger coil quenches due to high short-circuit current $\left(i_{\mathrm{S}}\right)$ flows through it. The trigger coil changes from superconducting state to normal state. As a result higher inductance appears in the main coil thus reduce the fault current. One leg of the bridge circuit consists of thyristors. The thyristors could be turned off immediately by removing the gate pulse signals. The fault current level could be sensed by using hall sensor. The fasted pos- 


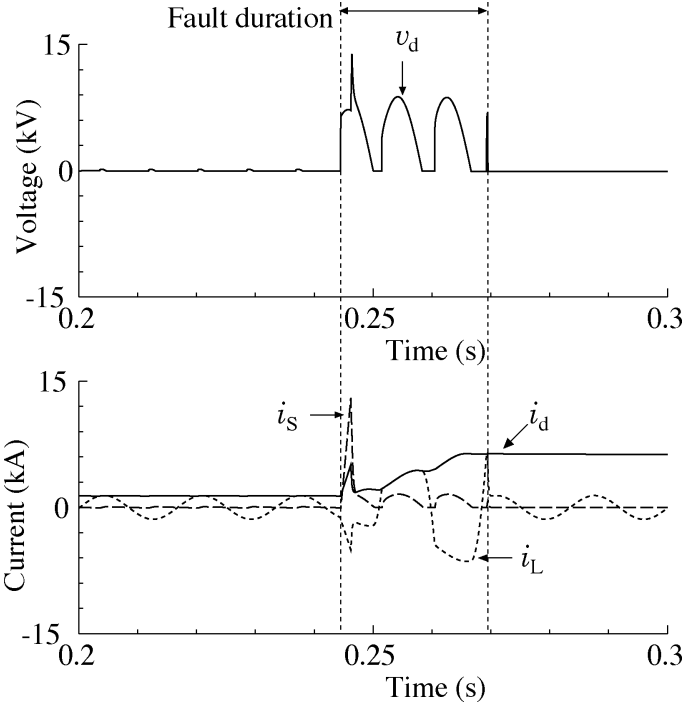

Fig. 2. EMTDC simulation waveforms of the SFCL during fault time. In the lower graph $i_{\mathrm{d}}$ and $i_{\mathrm{S}}$ indicate the main coil and trigger coil current respectively. The upper graph $v_{\mathrm{d}}$ indicates the main coil voltage at fault condition.

sible turn-off time could be a half cycle. Therefore, a half cycle circuit breaker with current limiter is possible in this case of SFCL. In current limiting mode the main coil carries the fault current without quenching. The critical current of the main coil should be high enough so that it can withstand the fault current. $\mathrm{S} / \mathrm{N}$ transition element is isolated using it in the secondary coil. If it is connected directly to the bridge circuit, the $\mathrm{S} / \mathrm{N}$ transition element will be over-heated due to high fault current. Such situation will increase the recovery time of the element or permanently damage it.

\section{SIMULATION RESULTS}

Before going to the experimental test, computer simulation of the SFCL circuit has been carried out. Mainly the current limiting performance in the fault condition has been performed. We carried out the simulation test of fault situation of the SFCL by using EMTDC (Electro-magnetic transient for DC system). A $6.6 \mathrm{kV}$ and $1 \mathrm{kA}$ system with 5 percent source inductance is considered. The mutual and leakage inductance of the 2 winding superconducting reactor is assumed to be $1 \mathrm{pu}$ and $0.1 \mathrm{pu}$ respectively. At the fault time, a step change of resistance is assumed for $\mathrm{S} / \mathrm{N}$ transition. The simulated output waveforms are shown in Fig. 2. The fault is made at -30 degrees phase for a duration of one cycle. In the graph (lower trace), the current of the trigger coil $\left(i_{\mathrm{S}}\right)$ has decayed quickly after $\mathrm{S} / \mathrm{N}$ transition occurred and then the line current $\left(i_{\mathrm{S}}\right)$ starts limiting. The inductor current $i_{\mathrm{d}}$ follows the $i_{\mathrm{L}}$ throughout the fault time. When fault is cleared, the $i_{\mathrm{L}}$ returns to the normal value. However, the $i_{\mathrm{d}}$ does not return instantly to the normal value, therefore, a circulating current flows through the diodes. This is known as freewheel current. After some time it comes to the normal value. In the upper trace the waveform represents the voltage across the main coil. In current limiting time, the source voltage appears across the main coil due to its high impedance for that particular time.

Normal rectifier type SFCL without using DC bias could produce significant voltage drop during load increasing time
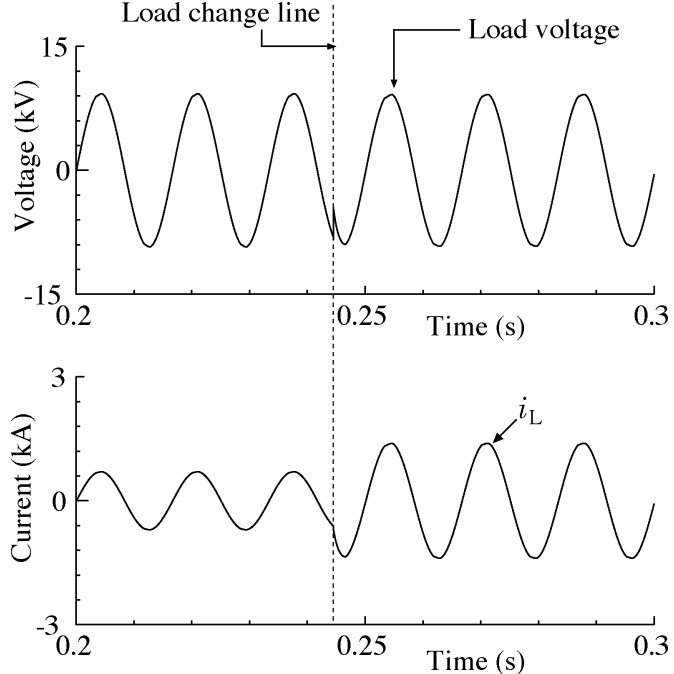

Fig. 3. EMTDC simulation waveforms obtained at load increasing time. A 50 percent load current change (in the lower graph) has been made at the vertical broken line but no significant voltage sag observed on the load voltage (in the upper graph).

TABLE I

SPECIFICATION OF THE SUPERCONDUCTOR COIL

\begin{tabular}{cc}
\hline \hline Wire & $\mathrm{NiTi} /(\mathrm{Cu}+\mathrm{CuNi})$ \\
Turns of main coils & 734 \\
Turns of trigger coils & 184 \\
Main coil's self inductance & $280 \mathrm{mH}$ \\
Trigger coil's self inductance & $18.6 \mathrm{mH}$ \\
Critical current: & $335 \mathrm{~A} \mathrm{@} \mathrm{1T}$ \\
Main coil & $179 \mathrm{~A} \mathrm{@} 1 \mathrm{~T}$ \\
Trigger coil & $200 \mathrm{~V}$ \\
Rated Voltage for primary & $100 \mathrm{~V}$ \\
Rated Voltage for secondary &
\end{tabular}

[6]. It is a disadvantage and reduces the system performances. We observe the voltage sag situation of our circuit during load changing period. The normal voltage and current set as $6.6 \mathrm{kV}$ and $0.5 \mathrm{kA}$ respectively. A step increase of 100 percent load current (from $0.5 \mathrm{kA}$ to $1.0 \mathrm{kA}$ ) has been considered. Although this is not usually happen in the power system however we like to see the performance the SFCL. The simulated waveforms are presented in Fig. 3. The output waveforms do not represent significant voltage sag on the load terminal (shown in the upper graph).

\section{EXPERIMENTAL CONDITIONS AND TeSt RESUlts}

We carried out the preliminary experiment using a superconducting transformer as a variable reactor. This readily available transformer has four superconducting windings. The specifications of the reactor has been presented in Table I. The air core type reactor is the prime target but the use of iron core would enhance its performance at normal operation and in the initial time of the fault. In rectifier type SFCL, introducing such reactor in the rectified circuit could easily saturate the iron core by the DC flux. The alternating flux in the reactor generated by the ripple current would not be effective because it is canceled by the induced short-circuited current of the trigger winding. 


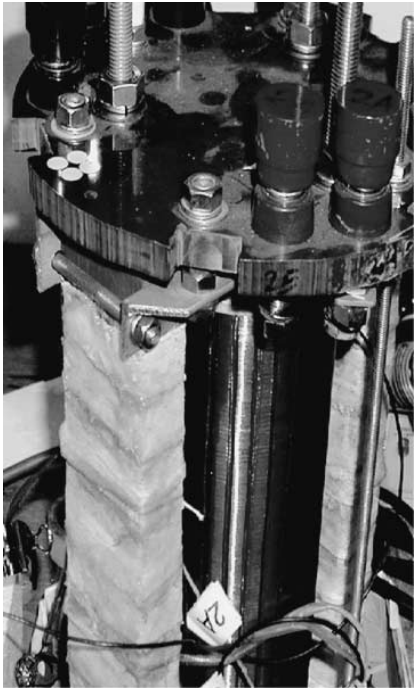

Fig. 4. This NbTi based superconducting device was used in the experiment.

Since the significant portion of the reactor current is DC therefore a nongap iron core reactor would not be so effective. On the other hand, iron core with big air gap would not saturate easily. In addition, it would decrease the ac loss of the reactor during normal operational time. Iron core would increase the coupling factor therefore decrease the leakage inductance of the reactor compared to air core type. In our experiment we used was the iron core reactor without any gap.

The superconducting device used in this experiment has been shown in Fig. 4. A microcontroller based thyristor gate drive signal and control circuit have been constructed for the SFCL. Very precise and accurate timing signals has been implemented digitally for making artificial fault so that fault could be made at different phase angles. The number of turns in the main coil is 734 and 184 in the trigger coil. The critical current of primary and secondary coils are $244 \mathrm{~A}$ and 179 A respectively (from short sample test at $1 \mathrm{~T}$ ).

We performed short-circuit test of one cycles duration. Fig. 5 depicts the test results. During $50 \mathrm{~V}_{\mathrm{rms}}, 10 \mathrm{~A}_{\mathrm{rms}}$ operational condition a fault is made at the zero crossing point of the line current $\left(i_{\mathrm{L}}\right)$ that is marked by the vertical broken line (left hand side). The trigger current reaches to maximum $108 \mathrm{~A}$ before it is quenched. A sharp quench of the trigger coil immediately introduces high impedance, as a result, it limit the fault current that is clearly shown in the line current $\left(i_{\mathrm{L}}\right)$ waveform. At the end of one cycle fault the maximum fault current of $i_{\mathrm{L}}$ has been observed $48 \mathrm{~A}_{\text {peak }}$. This value is only 3.4 times higher than the normal line current $\left(14.14 \mathrm{~A}_{\text {peak }}\right)$. We did not perform the fault test without SFCL, therefore, we could not compare how much it is reduced. The main coil current $\left(i_{\mathrm{d}}\right)$ free-wheels through the diodes. The upper graph of the diagram presents the main coil voltage. During the 1 cycle fault time the source voltage appears on the reactor.

One big advantage of using rectifier type SFCL is that it could also be used as circuit breaker along with its current limiting ability. In that case hybrid bridge circuit is required instead of simple diode bridge. We performed such test and the output shown in Fig. 6. Here the SFCL acts as a 1/2 cycle circuit breaker

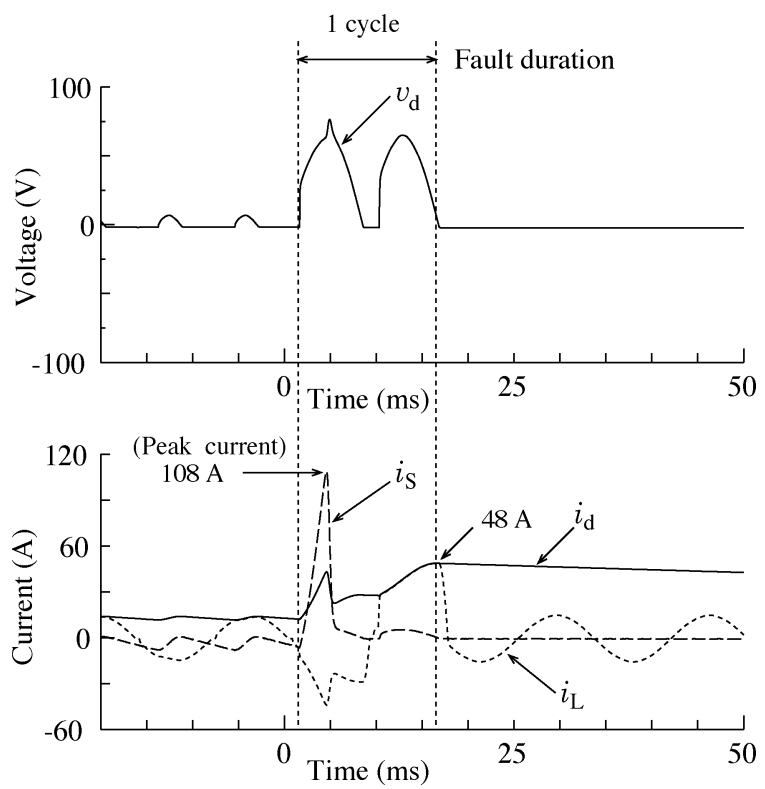

Fig. 5. The experimental waveforms obtained in the fault test. The fault is made for one cycle at the zero-crossing current marked by the vertical broken line. $i_{\mathrm{L}}$ and $i_{\mathrm{S}}$ indicate the limiting fault current and trigger current waveforms respectively. Upper graph represents the main coil voltage $\left(v_{\mathrm{d}}\right)$.

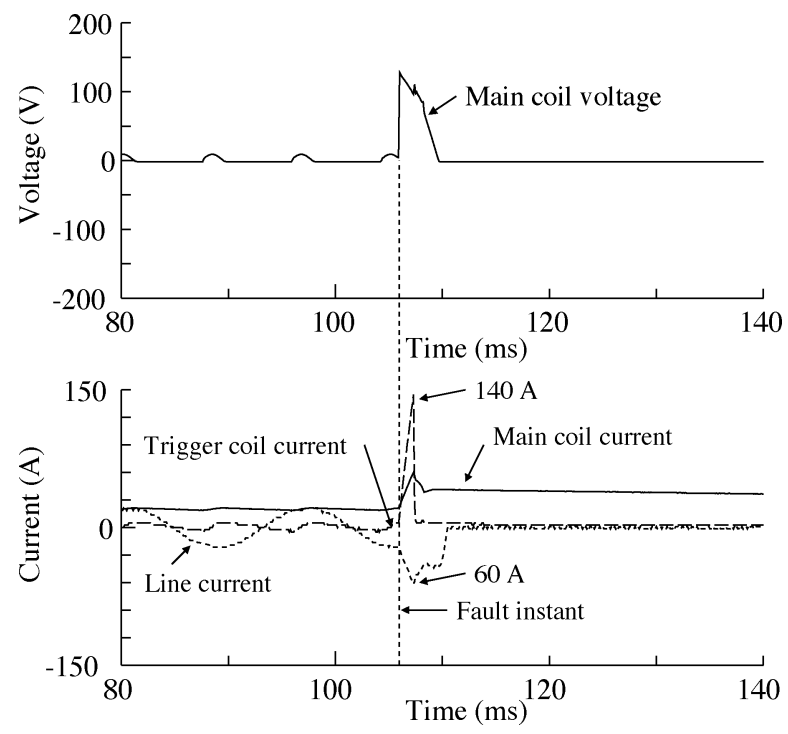

Fig. 6. The experimental waveforms obtained when fault is made at the -90 degrees of the current waveform. Current limiting as well as circuit breaking action have been observed on the waveforms. The waveform $\left(i_{\mathrm{L}}\right)$ shows that the fault current is limited to $60 \mathrm{~A}$ before it shutdown the system.

as well as a current limiter. In such a case, the line current monitoring hall sensor's output and the thyristor gate firing signals are interfaced to a logical control circuit. When the fault current reaches to a predetermined value the gate signals of the thyristors are turned off and the line is disconnected from the main source, thus works as a circuit breaker. In the experiment, the initial working voltage and current has been selected as $90 \mathrm{~V}$ and $15 \mathrm{~A}$ respectively before fault is made. This time the fault making point is $\mathbf{- 9 0}$ degrees in phase of current. In order to shutdown the system from over current, a predetermined value was set slightly upper than the twice of the value of the normal peak line current. The result clearly indicated that the current 


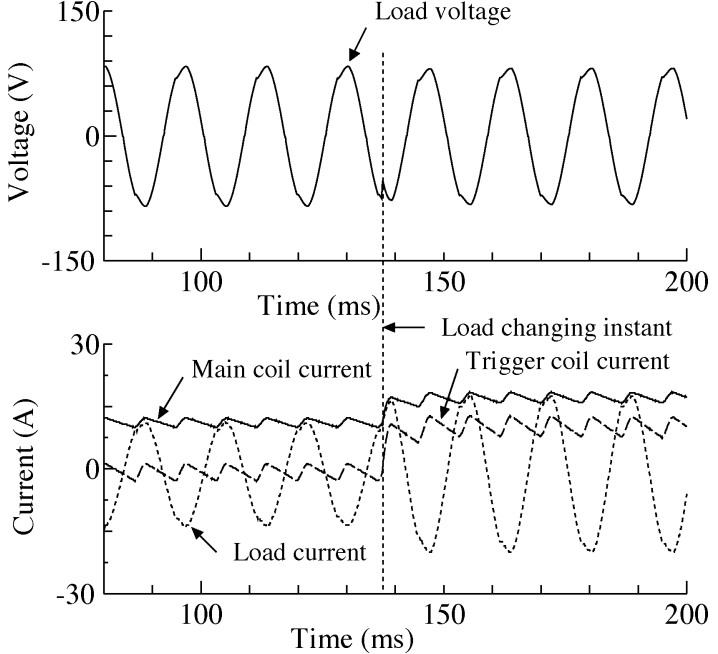

Fig. 7. Experimental waveforms obtained during load change test. Upper graph represents the load voltage and the lower graphs represent main, trigger and load currents.

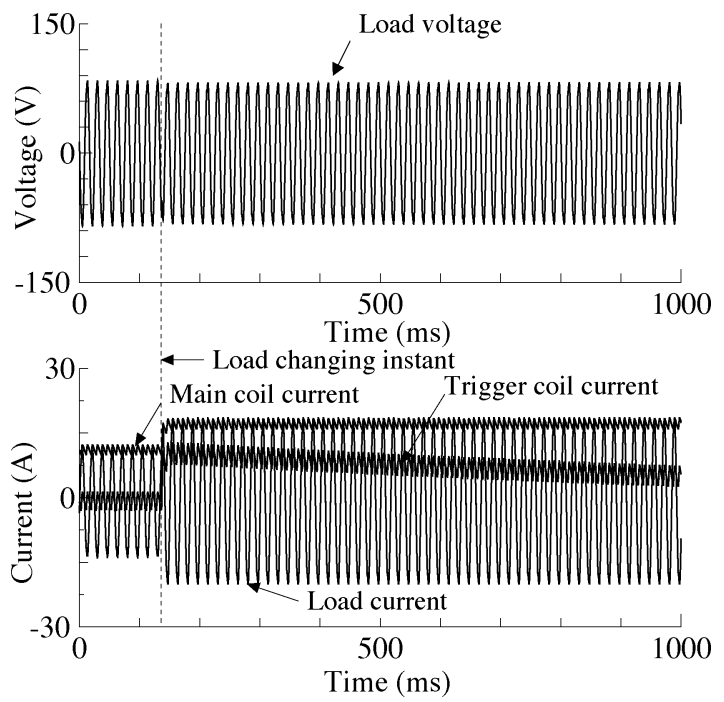

Fig. 8. Experimental waveforms obtained during load change test for longer duration.

has been limited after fault and finally it is disconnected from the power line. Fault happening, fault current limiting and circuit breaking all these process finished within a half cycle. It is noticed that the fault current reaches to a maximum value of $60 \mathrm{~A}$.

As long as the trigger coil current remains below its critical current value, there should not be appeared any voltage sag on the load voltage waveform due to the sudden load current change. The experimental waveforms shown in Figs. 7 and 8 de- scribed the situation about load changing effects during normal operational time. In Fig. 7, a step increase of about 50 percent load current (from 9.5 A to $14.3 \mathrm{~A}$ ) has been made to observe the voltage sag in the load voltage and current waveforms of the coils. No voltage sag problem has been observed on the waveforms. Again, the trigger current would rise up from normal label to a higher value during load increasing time but would come back to normal label after some period. Such situation has been clearly shown in the waveforms as shown in Fig. 8. Without using DC bias current in the reactor coil we could overcome the voltage sag problems by using this variable reactor concept. This is very important because the most of the time the system stays in normal operation and the load current does not remain constant.

\section{CONCLUSION}

Preliminary test has been performed and presented the results of Rectifier type SFCL with S/N transition trigger coil. It is a new rectifier type SFCL without using DC bias current through the main superconducting coil. Normal rectifier type SFCL requires DC bias current that is difficult to install. Without using DC bias current this SFCL gives expected results both in the fault and normal operational time. Such circuit could avoid voltage sag problems. As the DC bias source for the main coil has been avoided, the SFCL design would be simplified. It was also confirmed that the system could work as $1 / 2$ cycle circuit breaker with current limiter. Always on Static Induction Thyristor (SIT) can be used instead of conventional thyristor because of its simple trigger circuits. In future, $\mathrm{SiC}$ could be used in the rectifier circuit.

\section{REFERENCES}

[1] H. J. Boening and D. A. Paice, "Fault current limiter using superconducting coil," IEEE Trans. Magn., vol. MAG-19, no. 3, pp. 1051-1053, May 1983.

[2] T. Yazawa and E. Yoneda et al., "Design and test results of $6.6 \mathrm{kV}$ high- $\mathrm{T}_{\mathrm{C}}$ superconducting fault current limiter," IEEE Trans. Appl. Supercond., vol. 11, no. 1, pp. 2511-2514, March 2001.

[3] K. M. Salim, T. Hoshino, M. Nishikawa, I. Muta, and T. Nakamura, "Preliminary experiments on saturated DC reactor type fault current limiter," IEEE Trans. Appl. Supercond., vol. 12, no. 1, pp. 872-875, March 2002.

[4] T. Hoshino, K. M. Salim, M. Nishikawa, I. Muta, and T. Nakamura, "Proposal of saturated DC reactor type superconducting fault current limiter (SFCL)," Cryogenics, vol. 41, pp. 469-474, 2001.

[5] K. M. Salim and T. Hoshino et al., "Low voltage test of a single bridge rectifier type superconducting fault current limiter with noninductive reactor," presented at the 6th European Conference on Applied Superconductivity, Sorrento Napoli, Italy, September 14-18, 2003.

[6] K. M. Salim, T. Hoshino, A. Kawasaki, I. Muta, and T. Nakamura, "Waveform analysis of the bridge type SFCL considering load changing and fault time," IEEE Trans. Appl. Supercond., vol. 13, no. 2, pp. 1992-1995, June 2003. 